九州大学学術情報リポジトリ

Kyushu University Institutional Repository

\title{
Acoustic Emission Generation at Fracture Point During Tensile Tests in the Thickness Direction of Particleboard: Effects of the Board's Internal Structure
}

Lin, Han Chien

Laboratory of Wood Material Technology, Department of Forest Pruducts, Graduate school of Bioresource and Bioenvironmental Science, Kyushu University

Ishimoto, Mami

Nissin Software Cooperation

Fujimoto, Yoshiyasu

Miyazaki Prefecture Wood Utilization Research Center

Murase, Yasuhide

Lavoratory of Wood Material Technology, Devision of Biomaterial Science, Department of Forest and Forest Products Science, Faculty of Agriculture, Kyushu University

https://doi.org/10.5109/24427

出版情報: 九州大学大学院農学研究院紀要. 46 (1)，pp.103-112，2001-10-30. Kyushu University バージョン：

権利関係: 


\title{
Acoustic Emission Generation at Fracture Point During Tensile Tests in the Thickness Direction of Particleboard: Effects of the Board's Internal Structure
}

\author{
Han Chien LIN*, Mami ISHIMOTO**, \\ Yoshiyasu FUJIMOTO*** and Yasuhide MURASE****
}

\author{
Laboratory of Wood Material Technology, Division of Biomaterial Science, \\ Department of Forest and Forest Products Science, Faculty of Agriculture, \\ Kyushu University, Fukuoka 812-8581, Japan \\ (Received June 29, 2001 and accepted July 11, 2001)
}

\begin{abstract}
In order to clarify the acoustic emission (AE) characteristics during tensile tests conducted perpendicular to the plane of particleboard; we used a notch in the central portion of the thickness direction of the testing specimen designed for this study. We tested handmade particleboards representing a range of particle sizes, densities and resin contents for tensile stress while monitoring $\mathrm{AE}$ events. Two AE sensors (resonant frequency: $140 \mathrm{kHz}$ ) were mounted on the opposite faces of the test specimen. The location of each AE sensor at the center of the specimen was about $1 \mathrm{~mm}$ from the crack in the particleboard. We examined the influence of the internal structure factors on the behavior of $\mathrm{AE}$ generation during tensile tests.

The tensile strength of the particleboard was affected by particle size, board density and resin content. Results indicated that the higher the tensile strength, the greater the cumulative AE event counts $\left(T_{\mathrm{AE}}\right)$ monitored, which suggests that $T_{\mathrm{AE}}$ is involved in the internal structure factors, since tensile strength is closely related to $T_{\mathrm{AE}}$. The difference in measuring distance from the $\mathrm{AE}$ sensor to the fracture point significantly influenced the effective $\mathrm{AE}$ signal detected. The detected signal was attenuated because the distance in the internal bond tests was farther than that in the tensile tests. The load level at failure $\left(P_{\max }\right)$ was significantly related to the load level at the initiation of $\mathrm{AE}$ generation $\left(P_{6}\right)$ in the tensile tests. The negative tendency of this ratio $\left(R_{\mathrm{a}}\right)$, the stress level at the initiation of $\mathrm{AE}$ generation $\left(\sigma_{\mathrm{G}}\right)$ to that at failure (internal bond strength), became clear in the $P_{\max }$ or $T_{\mathrm{AE}}$ values.
\end{abstract}

\section{INTRODUCTION}

Particleboard (PB), a wood-based material, has been widely utilized in many industrial and domestic applications, such as the structural members in furniture or in architecture. It can be manufactured to different specifications or qualities for various applications. The performance of PB is governed by the properties of the wood species, the adhesive used, the manufacturing strategy and the production process (Kollomann et $a l ., 1986)$. PB testing during manufacturing and prior to use is an area of special importance. We have designed a test involving the fastening of PB internal structures to determine the tensile strength perpendicular to the plane (internal bond strength), which

\footnotetext{
* Laboratory of Wood Material Technology, Department of Forest Products, Graduate school of Bioresource and Bioenvironmental Science, Kyushu University

** Nissin Software Cooperation, Nagasaki 850-0035, Japan

*** Miyazaki Prefecture Wood Utilization Research Center 885-0037, Japan

***** Corresponding author (E-mail: ymurase@agr. kyushu-u.ac.jp)
} 
plays an important role in detailed PB analysis and provides direct information about the adhesion of the wood particles.

Acoustic emission (AE) techniques have for many years been considered the prime candidate for structural health and damage monitoring in loaded structures. They offer the user a number of inherent advantages, including continuous sensitivity in monitoring capabilities and the possibility of examining the entire volume of a structure. The increasing use of composite materials in loaded structures and their complex damage development has created a need for an efficient and reliable testing technique that can be used during the service life of these materials (Miller et al., 1978 and Surgen et al., 2000). Moreover, $\mathrm{AE}$ techniques clearly have the potential to serve as a continuous damage detection technique for composites and are one of the most effective methods for determining the relationships between the mechanical properties and internal structure of material (Fujii, 1997).

In order to evaluate the relationship between the $\mathrm{AE}$ and internal bond (IB) strength of wood-based composite panel materials (Beall, 1985) as well as the effect of internal structure factors on particleboard (Lin et al., 1994 and Fujimoto et al., 1997), we investigated $\mathrm{AE}$ generation during tensile tests perpendicular to the plane. We obtained basic information on the fracture mechanism of wood--based materials and PB during IB tests with $\mathrm{AE}$ monitoring. Fujimoto et al. noted that the higher the IB strength, the greater the cumulative $\mathrm{AE}$ event counts $\left(T_{\mathrm{AE}}\right)$ monitored, suggesting that internal structure factors were related to the IB strength. The ratio $\left(R_{\mathrm{a}}\right)$ of the stress level at the initiation of $\mathrm{AE}$ generation ( $\sigma_{\mathrm{G}}$ ) to that at failure (IB strength) was negatively correlated to both IB strength and $T_{\mathrm{AB}}$. Beall reported that density correlated well with IB strength for any of the materials (PB, MDF and $\mathrm{OSB}$ ), and with $\mathrm{AE}$ only when density was related to bond quality.

The $\mathrm{AE}$ signals detected in the $\mathrm{IB}$ tests were not $\mathrm{AE}$ generation at the fracture point (source). This was the AE signal during IB tests transmitted through the internal parts of the $\mathrm{PB}$ specimen that were detected by the AE sensor mounted on the surface of the loading block. Therefore, the $\mathrm{AE}$ generated at the fracture point during tensile tests in the thickness direction of $\mathrm{PB}$ remained to be examined. The objective of our research was to investigate $\mathrm{AE}$ generation at the fracture point and the development of minute fractures on various internal structure factors. We examined a test specimen, with a notch in the central portion of the thickness direction, using an AE monitoring system during tensile tests. This specimen shape was similar to the shape used to test fracture toughness, though the purpose of this study was not to measure fracture toughness. This study examined the AE generated by the tensile load. We measured the influence of the internal structure factors (particle size, board density and resin content) in the PB under tensile examination with $\mathrm{AE}$ signal monitoring.

\section{MATERIALS AND METHODS}

The single-layer particleboards were manufactured in the laboratory with phenol-formaldehyde adhesive (Oshika Shinko Co., Ltd. PB-1310) hot pressed at $30 \mathrm{kgf} / \mathrm{cm}^{2}$ and $180^{\circ} \mathrm{C}$ for $12 \mathrm{~min}$, with two $20 \mathrm{~mm}$ distance bars, based on the variable manufacturing factors shown in Table 1. 
Table 1. Various manufacturing conditions of particleboard.

\begin{tabular}{l|ll}
\hline $\begin{array}{l}\text { Variable } \\
\text { factors }\end{array}$ & $\begin{array}{c}\text { Particle size } \\
\text { (mesh) }\end{array}$ & On 8,8 to 12,12 to 24, and Through 24 \\
\cline { 2 - 3 } & $\begin{array}{c}\text { Board density } \\
\text { (nominal) }\end{array}$ & $0.5,0.6$, and $0.7\left(\mathrm{~g} / \mathrm{cm}^{3}\right)$ \\
\cline { 2 - 3 } & $\begin{array}{c}\text { Resin content } \\
\text { (dry solid basis) }\end{array}$ & 5,8, and $11(\%)$ \\
\hline
\end{tabular}

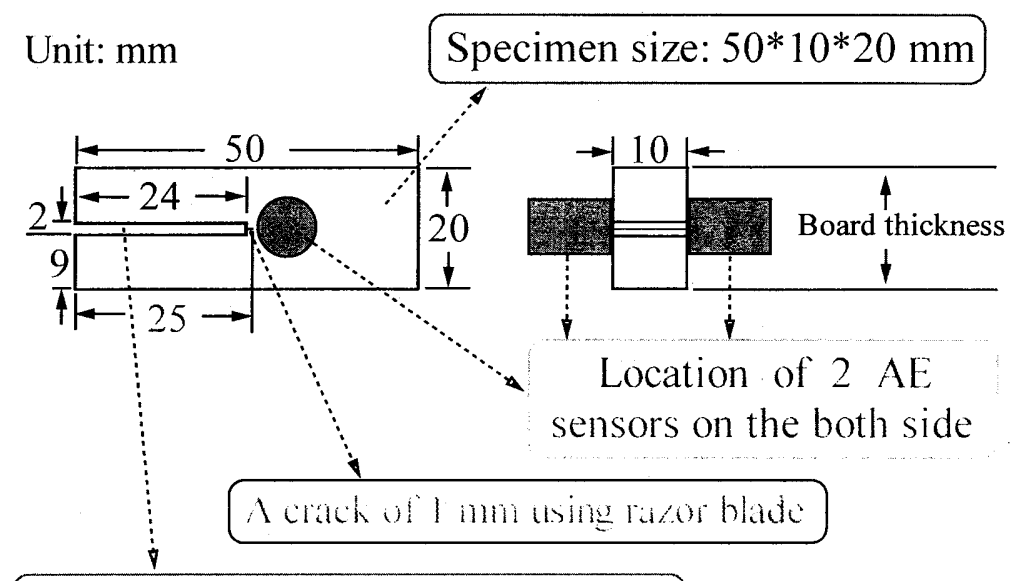

A notch by $2 \mathrm{~mm}$ width of band saw

Fig. 1. A diagram of the test specimen for detecting $\mathrm{AE}$ at the fracture point.

A sample test specimen and the $\mathrm{AE}$ sensor locations are shown in Fig. 1. All test specimens were cut into $50 * 10 \mathrm{~mm}$ pieces. A notch $24 \mathrm{~mm}$ in length was cut into the central portion of the thickness direction using a band saw with $2 \mathrm{~mm}$ width. The test specimens before the tensile tests with $\mathrm{AE}$ monitoring were conditioned to an equilibrium at $20^{\circ} \mathrm{C}$ with $65 \%$ relative humidity $(\mathrm{RH})$ for about four weeks. A $1 \mathrm{~mm}$ crack was made at the bottom of the notch using a razor blade before the tensile tests. Two AE sensors (NF Corporation, AE-901S, $140 \mathrm{kHz}$ ) $12 \mathrm{~mm}$ in diameter, were located on the opposite faces of the test specimen. The $\mathrm{AE}$ signal was measured during the tensile tests.

The AE monitoring apparatus and the tensile tests perpendicular to the test specimen plane are illustrated in Fig. 2. The two AE sensors were close to the specimen center, about $1 \mathrm{~mm}$ from the crack. Wax was used to adhere the $\mathrm{AE}$ sensors to the specimen. A tensile test was conducted using a universal testing machine (Shimadzu Corp., AG-100KNE) at a loading speed of $0.1 \mathrm{~mm} / \mathrm{min}$. Both $\mathrm{AE}$ signals detected during tensile tests were individually amplified by $40 \mathrm{~dB}$ using two preamplifiers (NF Corporation, 


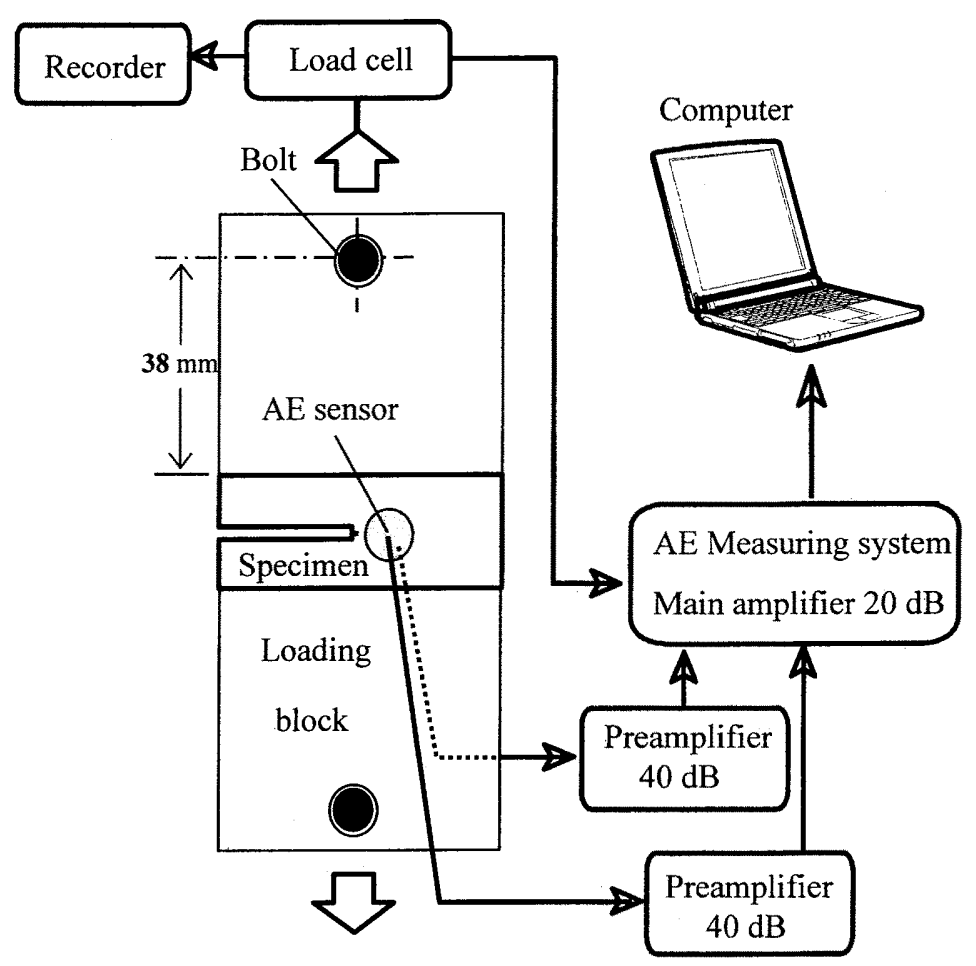

Fig. 2. Diagram of tensile test perpendicular to the plane of the test specimen, contained with the aid of the $\mathrm{AE}$ monitoring system.

$\mathrm{AE}-912$ ). The $\mathrm{AE}$ testing system (NF Corporation, 9406) was again amplified $20 \mathrm{~dB}$ by the main amplifier and discriminated at a threshold level of $300 \mathrm{mV}$ after using a $100 \mathrm{kHz}$ to $1.0 \mathrm{MHz}$ band pass filter. The load was recorded from the beginning until the failure on a recorder (Shimadzu Corp., AR-6422). The load level at the initiation of AE generation $\left(P_{\mathrm{G}}\right)$ until the loading level at failure $\left(P_{\max }\right)$ and the analysis of $\mathrm{AE}$ signals during the tensile tests were obtained from a computer. We examined the behavior of $\mathrm{AE}$ during the tensile tests due to the influence of particle size, board density and resin content using the parameters, $P_{\max }, P_{\mathrm{G}}$ and $T_{\mathrm{AE}}$ (Fujimoto et al., 1997). The AE amplitude distribution as one of the parameters was analyzed with the load level set as well.

\section{RESULTS AND DISCUSSION}

\section{Effect of particle size on tensile strength}

The influence of particle size on the IB strength and tensile strength in the thickness direction of the $\mathrm{PB}$ is shown in Fig. 3. There was a tendency for IB strength to increase as the particle size became larger. This was the same as a result we obtained previously (Fujimoto et al., 1997). The total particle surface areas increased when the particle size 


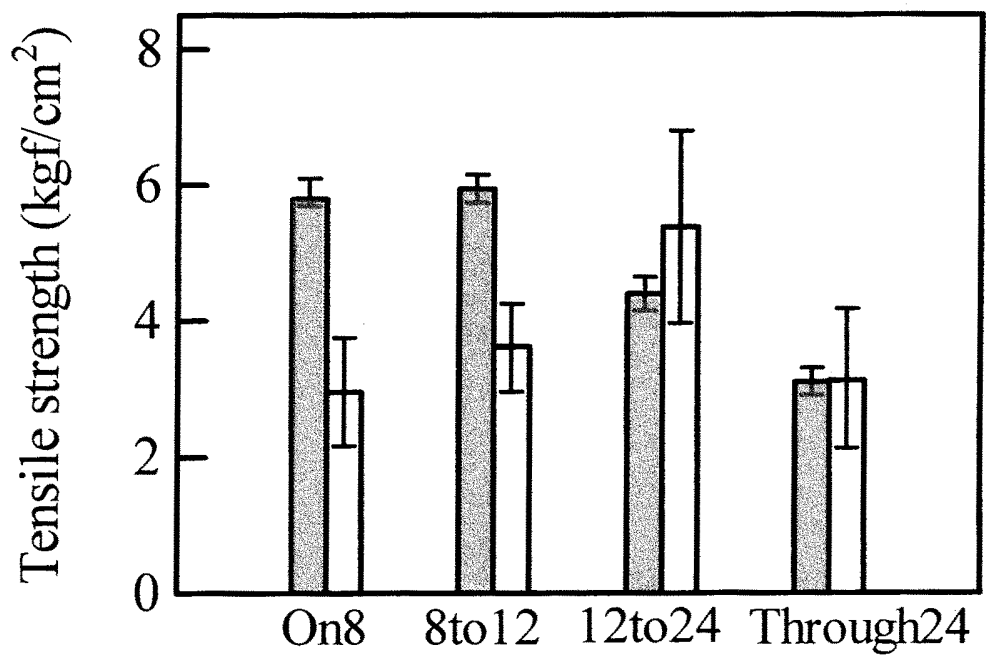

\section{Particle size (mesh)}

Fig. 3. Comparison of the IB strength with the tensile strength for particleboard specimen with various particle sizes.

Symbols: $\square$ : Tensile tests $(25 * 10 \mathrm{~mm})$

Note: $\quad$ IB tests $(50 * 50 \mathrm{~mm})$
$\quad$ Specimen size: length $*$ width.

became smaller, and the PB manufactured with smaller particles under the same resin content consisted of total bonded areas with insufficient or/and no resin. However, tensile test results showed that the PB made with 12 to 24 mesh particles had a higher tensile strength and that the PB with larger particles (on 8 and 8 to 12 mesh) had low tensile strength. This suggests that the area (bonded area and void area) of a testing specimen (about $24 * 10 \mathrm{~mm}$ ) in this experiment was small compared with the area of a specimen (about $50 * 50 \mathrm{~mm}$ ) in the IB tests. Therefore, the influence of the voids between the particles was remarkable in the case of PB made with larger particles because the bonded area was small for the testing specimen we used in this study.

\section{Particle size effect on tensile stress and $\mathrm{AE}$}

$\mathrm{AE}$ generation at the fracture point during tensile tests in the thickness direction for $\mathrm{PB}$ specimens with various particle sizes is shown in Fig. 4. Both the $P_{\max }$ and $T_{\mathrm{AE}}$ had the same tendency: the $\mathrm{PB}$ made with 12 to 24 mesh particles had the highest $P_{\max }$ and $T_{\mathrm{AE}}$, followed by the PB made with 8 to 12 , through 24 and on 8 mesh particles in that order. These findings suggest that the bonded areas and voids are involved in the tensile strength and the AE signals detected, because the bonded area is significantly related to the tensile strength (IB strength) (Han Chien Lin et al., 1994 and Fujimoto et al., 1997). In other words, the higher the tensile strength, the greater the $T_{\mathrm{AE}}$, which suggested that $T_{\mathrm{AE}}$ changed corresponding to the load level $\left(P_{\max }\right)$ in this tensile experiment. This was 

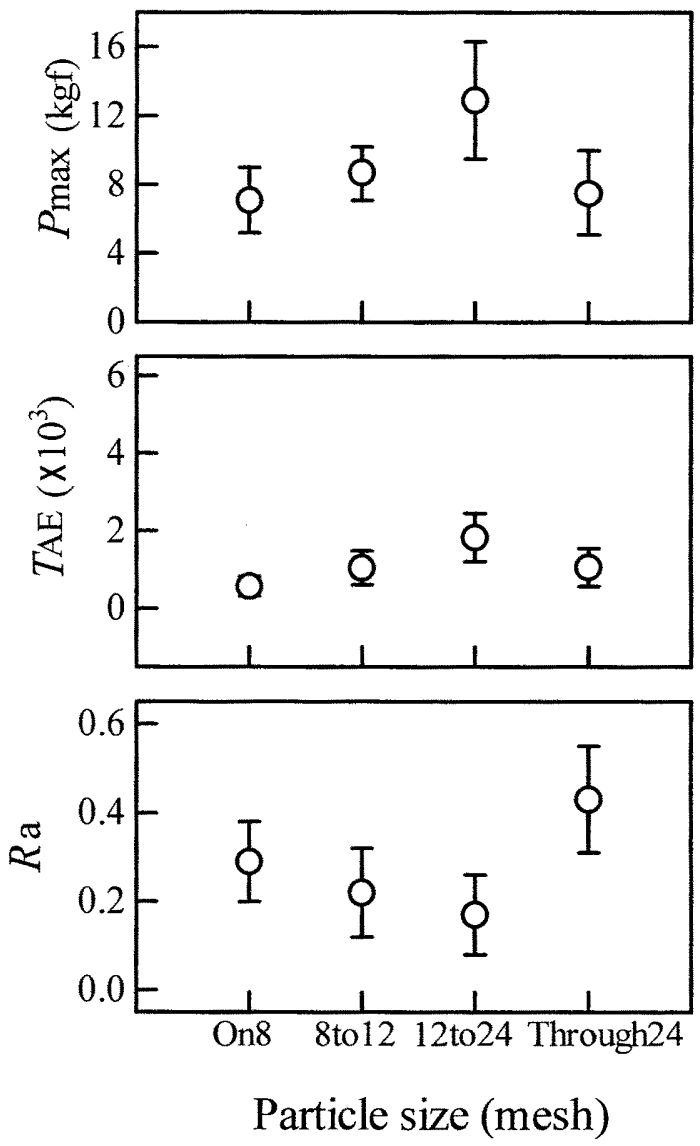

Fig. 4. Effect of particle size on $P_{\max }, T_{\mathrm{AE}}$ and $R_{x}$ for particleboard specimens.

the same result as that obtained in a previous study (Fujimoto et al., 1997) in which the IB strength was closely related to $T_{\mathrm{AE}}$. This therefore indicated that $T_{\mathrm{AE}}$ is related to the particle size, because the particle size influences the $P_{\max }$. As shown in the bottom of Fig. $4, R_{\mathrm{a}}$ shows a negative tendency of $P_{\max }$ and $T_{\mathrm{AE}}$. This indicates that the $P_{\mathrm{G}}$ value is significantly related to the $P_{\max }$ value. That is, $\mathrm{AE}$ at the fracture point generated later for the board with a higher tensile strength (that is, a larger $P_{\max }$ ).

Handmade PB was manufactured using particles 8 to 12 mesh at a density of $0.7 \mathrm{~g} / \mathrm{cm}^{3}$ with phenol-formaldehyde adhesive at $8 \%$ resin content. The $P_{\max }$ and $T_{\mathrm{AE}}$ in the IB tests and the tensile tests were compared according to the distance from the fracture point to the $\mathrm{AE}$ sensors. The $P_{\max }$ and $T_{\mathrm{AE}}$ values obtained from each test were normalized (Fig. 5). Results indicated that $\mathrm{AE}$ events in tensile tests became larger than that in IB tests at the same load level. In tensile tests the measuring distance from the fracture point to the $\mathrm{AE}$ sensor should be small, which suggests that the AE signal is attenuated because the distance from the fracture point to the AE sensor in the IB tests was farther than that in 


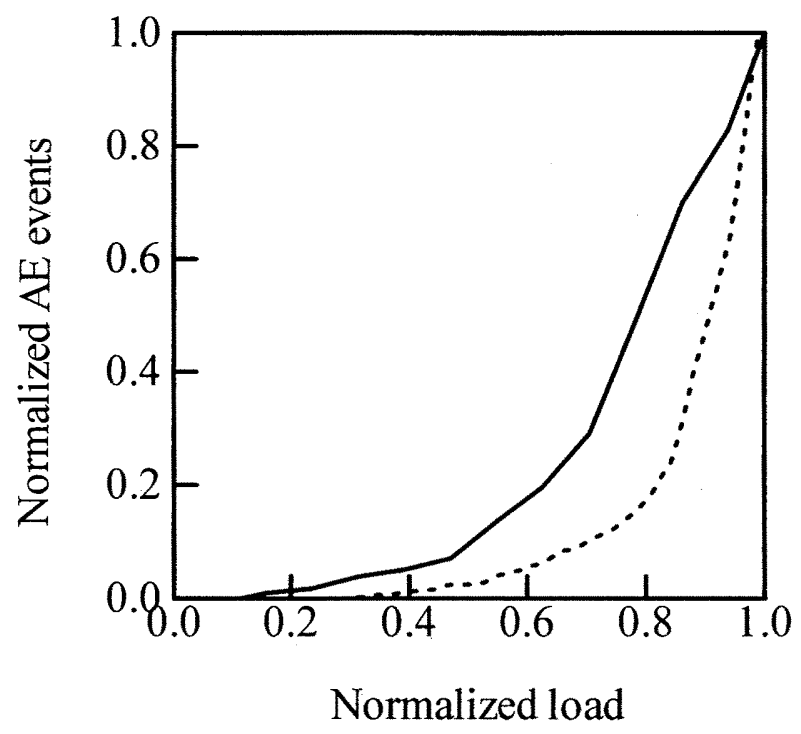

Fig. 5. Relationship between normalized load and normalized AE events for particleboard with the particle size of 8 to 12 mesh.

Symbols: - : AE detected directly at the fracture source (point) by tensile tests in this study.

- - : AE detected indirectly on the loading block by IB tests from the previous paper.

the tensile tests (Lin et al., 2001).

\section{Amplitude analysis on AE signals for various particle sizes}

Amplitude analysis is one of the most common means of evaluating AE signals when a material undergoes deformation. In general, the amplitudes of the voltage signals detected from the $\mathrm{AE}$ sensor are potted as a distribution and then compared with the load level (Miller et al., 1978 and Surgen et al., 2000). The influence of particle size on AE event, amplitude and load for PB specimens in varying particle sizes is shown in Fig. 6. The amplitude distribution at each $0.5 \mathrm{kgf}$ in the load range was analyzed. Results indicated that the same tendency was present for each particle size of board. Both the large and small amplitude increased as the loading level increased. The event for both type of amplitude increased relatively until the end of loading (fracture). That is, the higher the load level, the more the large or small the amplitude. This is because AE was the elastic energy that was released by the materials when they were under loading stress (Surgen et al., 2000). Moreover, the event of the small amplitude increased significantly before just reaching the load failure level. It is inferred that the energy was released greatly before fracturing and/or the amount of minute fracture was greater than the other load level during the tensile tests for PB specimens with various particle sizes. 

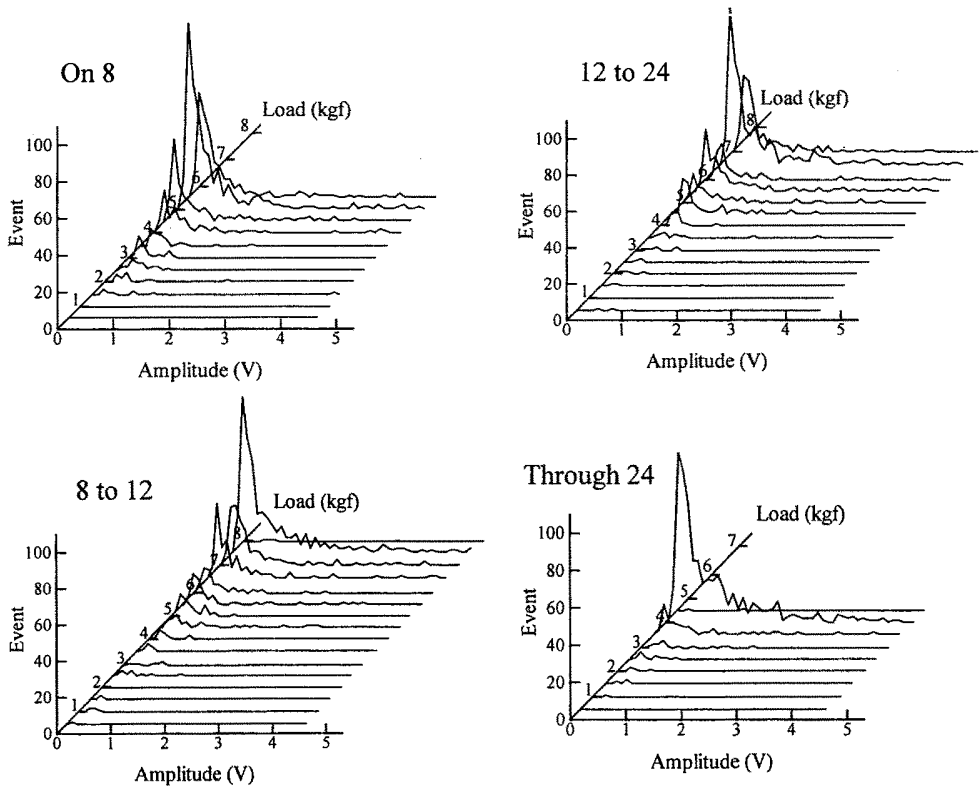

Fig. 6. Relationships between event, amplitude, and load for particleboard specimens with various particle sizes.
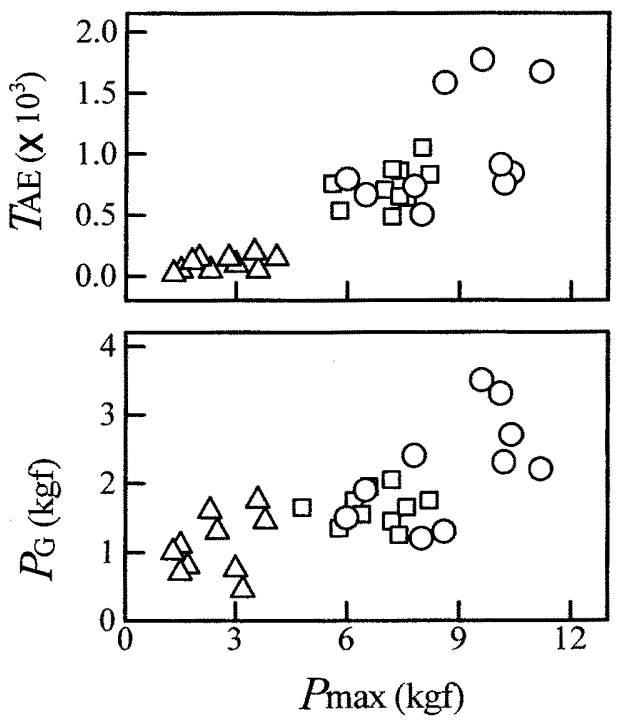

Fig. 7. Relationships between $T_{\mathrm{AE}}, P_{\mathrm{G}}$ and $P_{\max }$ for particleboard specimens with various board densities.

Symbols: Nominal board density $\left(\mathrm{g} / \mathrm{cm}^{3}\right)$ :

O: $0.7, \square: 0.6, \triangle: 0.5$. 


\section{Density effect on tensile stress and AE}

Single-layer PBs were manufactured using particle 8 to 12 mesh under 3 levels of board densities, $0.5,0.6$ and $0.7 \mathrm{~g} / \mathrm{cm}^{3}$, with phenol-formaldehyde adhesive at $8 \%$ resin content. The influence of density on $P_{\max }, T_{\mathrm{AE}}$ and $P_{\mathrm{G}}$ is shown in Fig. 7. $P_{\max }$ increased with increasing board density, and $T_{\mathrm{AE}}$ showed a tendency to increase as much as the density increased, which indicated that the density correlated well with the tensile strength and $\mathrm{AE}$ only when the board densification was related to the bonding quality (Beall, 1985). The $P_{\mathrm{G}}$ value showed a tendency to become larger as the density increased. This indicated that the effective adhesion area among the particles expanded as much as the density increased because the number of particles and the amount of adhesive increased (Lin et al., 1994 and Fujimoto et al., 1997). This suggests that $P_{\max }$ positively corresponds to the minute fractures that occur at the initiation of the load level $P_{\mathrm{G}}$.

\section{Resin content effect on tensile stress and $\mathrm{AE}$}

Handmade laboratory particleboards were manufactured using particle 12 to 24 mesh
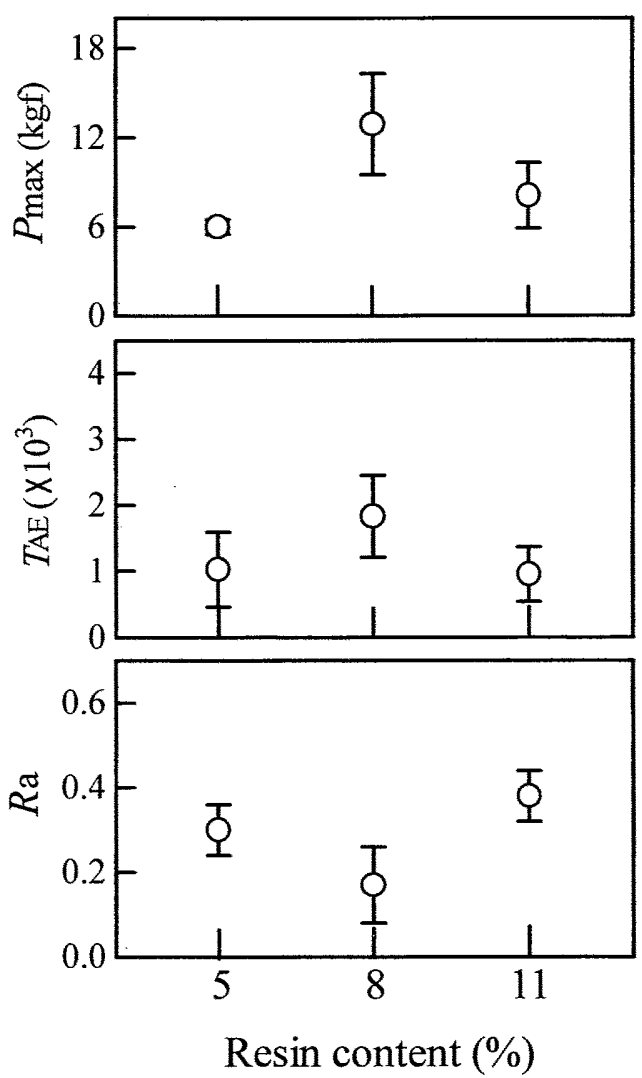

Fig. 8. Effect of resin content on $P_{\max }, T_{\mathrm{AE}}$ and $R_{\mathrm{a}}$ for particleboard specimens. 
for a nominal board density $0.7 \mathrm{~g} / \mathrm{cm}^{3}$ at 5,8 and 11 percent levels of resin content. Results indicated that $P_{\max }$ and $T_{\mathrm{AE}}$ at $8 \%$ resin content had the highest value, followed by 11 and 5 percent in that order (the top and middle of Fig. 8), whereas $R_{\mathrm{a}}$ showed the lowest value at $8 \%$ resin content and different $P_{\max }$ and $T_{\mathrm{AE}}$ tendencies in the tensile tests (the bottom of Fig. 8). In previous studies (Han Chien Lin et al., 1994 and Fujimoto et al., 1997), $P_{\max }$ and $T_{\mathrm{AE}}$ showed the largest value at $8 \%$ resin content in the IB tests. This same tendency was also shown in this experiment. In general, $P_{\max }$ and $T_{\mathrm{AE}}$ tended to increase as the resin content increased (Beall, 1985). However, an inner layer burst during manufacturing in $\mathrm{PB}$ manufactured with the particles through 12 mesh and phenol-formaldehyde adhesive at higher resin content (11\% and 14\%). This indicated that bursts in the inner layers were caused by imperfect adhesive hardening (Fujimoto et $a l ., 1997)$. The $P_{\max }$ and $T_{\mathrm{AE}}$ values at $11 \%$ resin content were lower than those at $8 \%$. These test results are influenced by the test parameters $\left(P_{\max }\right.$ and $\left.T_{\mathrm{AE}}\right)$ just as they were in previous studies. $R_{\mathrm{a}}$ therefore showed the same tendency as the reported in previous work, which had its highest value at $11 \%$ resin content.

\section{ACKNOWLEDGEMENTS}

The authors are grateful to the Dantani Corporation, Japan, for providing the experimental wood particles, and to Oshika Shinko Co., Ltd., Japan, for offering experimental adhesive, PB-1310. We sincerely appreciate the research assistance of Mr. Junichi Kawaba, Faculty of Agriculture, Kyushu University Graduate School.

\section{REFERENCES}

Beall, F C. 1985 Relationship of acoustic emission to internal bond strength of wood-based composite panel materials. Joumal of Acoustic Emission, 4(1): 19-29

Beall F C 1985 Effect of resin content and density on acoustic emission from particleboard during internal bond testing. For Prod J 36(7/8): 29-33

Fujii, Y. 1997 Application of AE monitoring to forest products research. Mokuzai Gakkaishi, Japan, 43(10): 809-818

Fujimoto, Y., Han Chien Lin and Y. Mataki 1997 Behavior of acoustic emission generation during tensile test perpendicular to the plane of particleboard -Particularly, effect of internal structure factor of board -. J. Soc. Mat. Sci., Japan, 46(4): 413-418

Kollomann, Franz F. P., Edward W. Kuenzi and Alfred J. Steam 1986 Principles of Wood Science and Technology. Vol. 2, pp 339-450, 463-472 and 489-491

Lin, Han Chien, Y. Fujimoto and Y. Mataki 1994 Effects of various factors on AE in Ioading perpendicular to plane of particleboard. Abstracts of The $44^{\text {th }}$ Annual meeting of The Japan Wood Research Society, 44: 126

Lin, Han Chien, Y. Fujimoto and Y. Murase 2001 Behavior of acoustic emission generation at fracture point during tensile tests in thickness direction of particleboard. - Effect of internal structure factor of board -. Abstracts of The 51/2 Annual meeting of The Japan Wood Research Society, 51: 246

Lin, Han Chien, Y. Fujimoto and Y. Murase 2000 Characteristic of ultrasonic wave transmission in particleboard. The proceedings of the $5^{\text {th }}$ Pacific Rim Bio-Based Composites Symposium in Canberra, Australia 5: $478-484$

Miller, R. K. and Mclintire P. 1978 Nondestructive testing handbook. Acoustic emission testing, $2^{\text {nd }}$ ed., volume 5. American Society for Nondestructive Testing, Ohio (English), pp 11-22, 34-38, 45-62

Surgeon, M., C. Buelens, M. Wevers and P. De Meester. 2000 Waveform based analysis techniques for the reliable acoustic emission testing of composite structures. Joumal of Acoustic Emission. 18 $34-40$ 